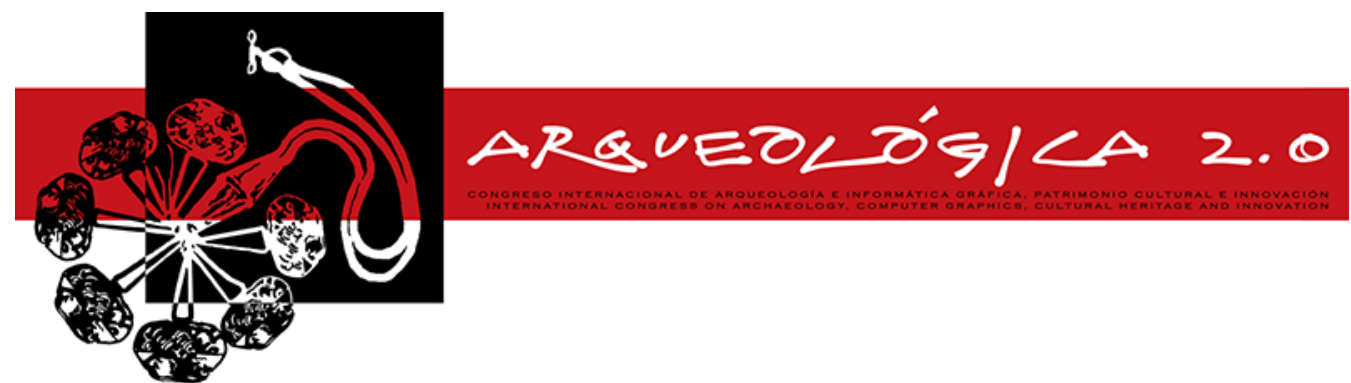

Proceedings of the $8^{\text {th }}$ International Congress

on Archaeology,

Computer Graphics,

Cultural Heritage and Innovation

'ARQUEOLÓGICA 2.0'

in Valencia (Spain),

Sept. 5-7, 2016

DOI: http://dx.doi.org/10.4995/arqueologica8.2016.4210

Received: 21/04/2016

Accepted: 27/06/2016

\title{
CASTLE4D: AN ARCHAEOLOGICAL INFORMATION SYSTEM BASED ON 3D POINT CLOUDS
}

\author{
Andrea Luczfalvy Jancsó ${ }^{a, b,{ }^{,},}$Benoît Jonlet ${ }^{a}$, Pierre Hallot ${ }^{a}$, Florent Poux ${ }^{a}$, Patrick Hoffsummer ${ }^{b}$, \\ Roland Billen ${ }^{\mathrm{a}}$ \\ a Geomatics Unit, Department of Geography, University of Liège, Quartier Agora, Allée du 6 Août 19, 4000 Liège, Belgium. \\ andrea.luczfalvyjancso@doct.ulg.ac.be; bjonlet@ulg.ac.be; p.hallot@ulg.ac.be; fpoux@ulg.ac.be; rbillen@ulg.ac.be \\ ${ }^{b}$ European Archaeometry Centre (CEA), University of Liège, Quartier Agora, Allée du 6 Août 19, 4000 Liège, Belgium. \\ phoffsummer@ulg.ac.be
}

\begin{abstract}
:
During the past decade, the implementation of 3D visualization and Geographic Information System (GIS) in archaeological research has increased and is now well established. However, the combination of these two factors remains rather complicated when faced with archaeological data. Some of the characteristics of this discipline impose the development of applications that will be able to cope with all of the specificities of archaeological data. Our research aims to create an Archaeological Information System (AIS) that will gather all of the characteristics of an archaeological work. In order to develop such an AIS, our first step was to identify its purposes and consequently, the features that should be available to the users. As it is destined to help with archaeological research, it is therefore of the outmost importance that the particularities of such a study are also taken into account. Moreover, the AIS is intended to incorporate point clouds that serve as a base for the three-dimensional model. These 3D point clouds result from the use of photogrammetry and/or lasergrammetry and, at a later stage, will be inserted into a GIS similar structure. The archaeological data will then be linked to the relevant section of the 3D model. However, these various stages and during the development of the AIS itself, we will encounter a series of issues that require to be addressed in order to produce a working system. This paper aims to identify and define the AIS characteristics as well as the issues and obstacles that we are going to face so that this system becomes a functional tool for archaeological research.
\end{abstract}

Key words: digital archaeology, 3D point clouds, AIS, GIS, 4D.

\section{Introduction}

Archaeological research is characterized by the various types of documents and data that are taken into account while examining a site, a monument or an artefact. Results are based on their analysis (Laurenza and Putzolu 2001). Yet, along with the speedy evolution of the digital world, archaeologists can now rapidly produce big amounts of data (Entwistle et al. 2009). All of this information needs to be examined in order to draw pertinent conclusions.

In order not to lose sight of any of the dataset, we are currently developing an Archaeological Information System (AIS) based on 3D point clouds and considering the temporal aspect as a fourth dimension. With this, every shred of data is linked to the area on which they provide information.

The development of the 4D AIS is taking place in our research project CASTLE4D in which several Belgian castles located in the province of Liège are being studied under the light of archaeological sciences and geomatics. This procedure enables the elaboration of new research topics as well as new data that will lead to a better understanding of the history of each castle site.

This paper aims at presenting the features of the 4D AIS that we are developing as part of our doctoral research. To achieve this, a state-of-the-art will summarize today's use of 3D representation in archaeological research. Following this, the system's main characteristics will be named and described. Finally, we are going to address the issues that we are going to face and the reasons why it is necessary for this project to deal with them.

\section{Current 3D models}

Now, as far as archaeological research is concerned, 3D models are generally used for visualization, reconstruction, measuring and documentation (Entwistle et al. 2009).

`Corresponding Author: Andrea Luczfalvy Jancsó, andrea.luczfalvyjancso@doct.ulg.ac.be 
its angles, depths and structures. Volumes are easier understandable and smaller pieces as well as objects can be handled without damaging them (Laurenza and Putzolu 2001; Paliou 2013).

Virtual reconstruction offers different possibilities: theories can be checked, a better understanding can be reached where only a small part is preserved and it is a frequently used tool for vulgarisation purposes. In addition to the elements that remain and, if it applies, are still situated at their original location, the missing parts are reconstructed based on previously gathered data (Hallot et al. 2015).

Photogrammetry and lasergrammetry produce 3D models that include a possibility to perform distance or angular measurements. Yet, in the first case, local or georeferenced coordinates must be considered in order to assure the geometric coherence as well as the scale of the reproduced element. Once the coordinates are inserted, measurements can be taken and crosssections or plans can be extracted (Ballarin et al. 2013).

Three-dimensional recording of cultural heritage acquires a great importance since it assists in preserving monuments and objects that are likely to face natural disasters, wars or degradation over time (Doulamis et al. 2015; Entwistle et al. 2009).

All of the examples listed above consider a static 3D model. Once the data has been recorded and the threedimensional representation has been assembled or, in some cases, reconstructed, the final product is rarely altered. It is analysed as a whole or through segments. In accordance with the research and the communication purposes, it is often inserted into a map, an information system or a visualization tool. However, its appearance is conserved and as for the data, it is stored next to it, but seldom in the 3D model itself (Dell'Unto et al. 2016).

$3 \mathrm{D}$ models are slowly starting to serve other purposes besides those already discussed above. Indeed, some researchers are developing them into analytical tools: data is accessible and managed through them (Ardissone et al. 2013; De Roo et al. 2013a; Dell'Unto et al. 2016; Houshiar et al. 2015; Koehl et al. 2008). Moreover, spatial relations between findings or between zones can be easier understood than with a twodimensional approach (Belussi et al. 2015; Dell'Unto et al. 2016; Paliou 2013; Robles Ortega et al. 2015).

\section{Ideal components}

Within our research, we aim at developing a 4D AIS (mixing 3D and the temporal aspect) especially created in order to deal with archaeological information that is characterized among others by uncertainty, imprecision, ambiguity and incompleteness (De Roo et al. 2013a; De Runz 2008). Currently, these aspects are not efficaciously managed in recent GIS-based tools. Time, which is of a great importance in archaeological studies, represents a fourth dimension in addition to the betterknown 3D model (De Roo et al. 2014).

Our planned system should ideally provide us with a range of possibilities. With these, a better understanding of the current research object should be obtained. The system should help to analyse the actual study object as well as all of the collected data related to it, to visualize the available sources and to record different work stages.

\subsection{D model}

A 3D point cloud of the studied object will be considered as the virtual working space that is destined to organize and group every bit of information gathered during fieldwork and sources examination (Cripps 2013). This interface will also serve as a place to gain an overview of current studies that evolve daily and to exchange ideas and theories between all of the researchers (Landeschi et al. 2015; Laurenza and Putzolu 2001).

The point cloud will be acquired using photogrammetry and/or lasergrammetry with a geodetic reference system (local or national grid). However, a georeferenced 3D model can also be considered for an on site research since it will ease the integration of various other elements surrounding the research site that can provide new insights (Ardissone et al. 2013).

There are several reasons that lead to the choice of a three-dimensional representation. Recent technological advances allow a quick and accurate data acquisition. In addition, users can sort of "walk around" in the virtual environment. So, even if it does not substitute for an on site study, it can nevertheless support the outdoor work by providing a way to access out of reach sections. Consequently, they will be easier to observe since such a $3 \mathrm{D}$ model can be turned and observed from every point of view (Koehl et al. 2008).

\subsection{Data storage and consultation}

In addition to the 3D model, a database is planned to store every known source, document and other data. The file types used by archaeologists are various, which generally implies that numerous softwares are needed to consult them (De Roo et al. 2014). Therefore, each of them will be accessible through the semantic context information added to the virtual reproduction. This way, the data will be directly linked to the element or part of the research object it holds information about (Dell'Unto et al. 2016; Doulamis et al. 2015; Koehl et al. 2008; Landeschi et al. 2015; Manferdini et al. 2008; Wulff and Koch 2013). Therefore, if the coordinates are known, the data will be inserted in the same location than in real life. Unlike a plan or a drawing, this kind of information will no longer be projected in a two dimensional presentation. This procedure will provide a better understanding of the spatial relation between every element. Furthermore, some questions inherent to a $2 \mathrm{D}$ projection may also be answered through a more accurate representation of the spatial distribution and by using the spatial reasoning capabilities of the supporting GIS system (Dell'Unto et al. 2016; Paliou 2013; Robles Ortega et al. 2015).

This data storage will also allow the researcher to consult all of the available sources and documentation (Coughenour et al. 2015; Laurenza and Putzolu 2001). Since they are linked to the part of the $3 D$ model that they contain information about, it will be possible to visualize all of the data related to specific segments the researcher is interested in at a given time. 


\subsection{Data production}

The 3D point cloud itself can also be exploited. Orthophotos, profiles, plans and cross-sections can be created, distances as well as angles measured (Ballarin et al. 2013). The model itself can be segmented in order to focus on a smaller sector (Koehl et al. 2008). Every action can be recorded and the results will then be added to the previous data.

\subsection{Topographic setting and environmental analysis}

Since the model is based on a georeferenced framework, topographic information such as maps, LiDAR datasets or geological context is included transparently. All the information is interoperable (Entwistle et al. 2009).

All of this added data about the surrounding territory can then be integrated into the research. Therefore, analyses combining the cultural heritage and its physical environment can be carried out. Some of the possible applications could be territorial visibility, positioning in relation to the natural environment or even the provenance of the materials (Entwistle et al. 2009). Other analyses may also be available based on the nature of the data used for the research.

Moreover, the ancient perception of space and its appropriation by its past inhabitants can also be studied through this interactive system (Dell'Unto et al. 2016; Paliou 2013).

\subsection{Time management}

Time is the key element in an archaeological research. However, a 3D model provides a static view of a recorded monument, site or object (De Roo et al. 2013a; De Roo et al. 2013b). Within the 4D AIS, the researcher should therefore be able to assign a time frame to each element (Belussi et al. 2015; Doulamis et al. 2015; Manferdini et al. 2008). Once this step is done, he could then choose which sections should be visible by applying a terminus post quem and a terminus ante quem. A timeline feature is also being considered. This tool will be able to display chronologically the appearance and, in some cases, the disappearance of the timed parts (Doulamis et al. 2015; Hallot et al. 2015; Van Ruymbeke et al. 2015).

\subsection{Work flow and developed theories}

Since the 4D AIS will provide a virtual workspace, it will be interesting to save different versions in order to be able to get back to them if new ideas or new data are inserted.

Another option will be the opportunity to register elaborated theories (Van Ruymbeke et al. 2015). Along with these, the data that they are based on will also be included. This will provide an overview of the used information and it will support the discussion about the pertinence of each of the generated hypotheses.

\subsection{Adaptability}

Archaeological study objects come in various types, forms, sizes and complexity levels. In addition to that, as an archaeological research is also characterized by uncertainty, imprecision, ambiguity and incompleteness (De Runz 2008), it is of the outmost importance that a 4D AIS that deals with these features has to be malleable (Haskiya 2002).

Fieldwork is another argument supporting this feature. In those cases, data is collected on multiple days, months or even years. New spaces can be uncovered, the research site can be increased in size and unexpected events are numerous (Laurenza and Putzolu 2001). A $3 \mathrm{D}$ point cloud is a practical solution to which new scans can be added. This way, the old appearance as well as the new one can overlap and therefore, they are easier to compare and study together.

\section{Issues}

The above sections cite and describe the ideal components of our application. However, as already stated, it deals with an ideal. Therefore, we will now address the issues with which we will have to cope in order to reach our goal.

\subsection{Development of the Archaeological Information System}

Although Geographic Information Systems are widely used for archaeological research, some of the properties of archaeological data are complicated to integrate in such a structure (De Roo et al. 2013a). In addition, as research on archaeological subjects continuously grows and evolves (Haskiya 2002), the AIS should include a virtual workspace in order to allow at the same time consultation of already recorded information, navigation in the 3D model, working on the theories as well as adding and modifying data. As the newly inserted entries can affect previously registered work steps and the current development of theories, a notification needs to be issued in order to highlight all the sections that are affected by an extension. With this, the researcher can review them and update his theories.

It will be necessary to develop an application able to handle all these aspects at once. At the same time, all of these options need to be organized and clearly presented. A structured display will also have a big impact for an easier apprehension of the different elements in an AIS based on a 3D model.

One of the main features of this system will be to be able to handle modification to its basic presentation (Dell'Unto et al. 2016). Since every archaeological study or site has its own characteristics, new categories need to be inserted without disrupting the stored data beforehand. This should also apply when adding an extension to the 3D model: the links, which were previously established between the data and an older state of the 3D point cloud, have to be conserved without any disruption.

\subsection{The multivocality of archaeological data}

As Cripps (2013) mentions it, archaeological data consists mostly of various and fragmentary information and archaeologists often construct multiple narratives based on the collected data. This multivocality forces the development of an application that is able to adjust to the versatility of archaeological studies (Dell'Unto et al. 2016). 
Amongst those characteristics, different elements need to be addressed. The temporal aspect is one of the most important ones. However, the integration of such a parameter in an Information System is still limited as an attribute. Moreover, time is not a constant feature as far as archaeological data is concerned and its delimitations are often fuzzy (Belussi et al. 2015; De Roo et al. 2013b).

Therefore, this 4D AIS, as we conceive it, should propose the opportunity to hide unwanted parts of the $3 \mathrm{D}$ model and the information that is linked to it. Of course, this procedure will not be able to automatically reconstruct the parts that disappeared over time, but it can assist the archaeologist by hiding unneeded data and visual information. This option could be a useful tool for the researcher to understand use of space as well as the reasons that lead to later modifications. For this concept to be effective, the semantic classification of the point cloud will be crucial. Indeed, it will be very important to sort the data correctly and to link it to the appropriate sections of the 3D model (Doulamis et al. 2015; Wulff and Koch 2013). The attributes that will be added to them will also need to be carefully selected so that the information, if it is linked to two or more parts, is still available even if some of those sections are not on display.

Since archaeological data is multivocal, as Van Ruymbeke (2015) states, different theories can be elaborated. In order to keep track of their evolution, saving a new development should replace the old entry. This will allow to review the thought process that led to the current interpretation and to assess the links that have been created between some of the hypotheses.

\subsection{Data volume}

As the AIS is destined to store almost all of the data about the study object the archaeologist is working on, the number of files can vary from small to quite large depending on the stage of the research and of its extend (Coughenour et al. 2015).

The 3D model on its own contains billions of points that are defined by $X, Y$ and $Z$ coordinates and semantic information. Laser scanners also produce photographic panoramas in order to colorize the point cloud. Each of these panoramas can range from 70 megapixels (for the Trimble TX5) (Trimble 2012) to 700 megapixels (for the Leica ScanStation P30) (Leica 2015). Therefore, depending on the size of the studied area, the resolution and the quality of the recorded data, the size of the 3D model can begin with a few gigabytes with no maximal size.

As for the collected documentation, it can present itself in different file types and formats going from a simple text document to a high-resolution image scan. As for the size of all of these entries, it can fluctuate from almost nothing to a perpetual addition of data (Coughenour et al. 2015).

In order to consider this huge amount of data, solutions will need to be set up so that the application is not slowed down.

\subsection{Standardization of the file formats}

All of the used file formats will need to be standardized and compatible with one another. This will allow to switch from the system to another one as well as to share the results of the research with other parties (Houshiar et al. 2015; Laurenza and Putzolu 2001; De Roo et al. 2013a). Therefore, already existing and widespread formats are going to be selected in order to ensure an easy data transmission and sharing.

\section{Conclusion}

In this paper, we presented the main features of the system we are currently developing within research project CASTLE4D. This application is destined to support archaeological research and fieldwork by providing a virtual workspace which allows the researcher to incorporate all of the available data to a 3D model of its research object as well as to analyse the information and to export the results of his study.

The ideal components we identified for this system include a 3D model based on a point cloud, data storing and consultation as well as data production based on the analyses carried out by the researcher. Additionally, the user will be presented with the possibility to insert the study object into its surrounding topographical and environmental context and a temporal feature that will assist the researcher sort and visualize the interesting data for a specific topic. Furthermore, work status and theories can be saved in order to get back to them on a later stage. This will enable the user to document the thought process that led to the conclusions. Finally, an emphasis is set on adaptability since every archaeological research has its own particularities.

However, along with this hypothetical application, a number of issues have to be addressed in order to create a system that will work the way it is supposed to and that will not collapse when some modifications are necessary in order to adapt to some singularities of the research object.

First, the AIS has to be developed according to the needs of archaeological research. In addition to this, the AIS interface will have to be clear in order to be easily used by the researcher. Indeed, several aspects such as visualization, the workspace and the storage will be accessed through the graphical interface.

Then, we have to make sure that the multivocality of an archaeological research is taken into account by the system as well as the temporal aspect. At the same time, the system must be able to handle frequent modifications, addition of data and new links between different entities. All of this has to happen without deleting or changing any of the previous constructed relations.

Going on, data volume will have to be addressed since the totality of the inserted data (point cloud and other information) will be of a very large size which could greatly slow down. Therefore, different approaches will be tested so that the most appropriate one is selected.

Finally, the file formats will be standardized. This step will reduce a few variables that could impeach the good functioning of the application. The choice of widespread formats enables compatibility with other systems. 
The next step of this research will be the development of the above defined AIS. A prototype will be worked out and tested on the castle of Franchimont (Theux, province of Liège, Belgium) before applying it on other study objects.

\section{References}

ARDISSONE, P., BORNAZ, L., DEGATTIS, G. and DOMAINE, R., 2013. A 3D Information System for the Documentation of Archaeological Excavations. International Archives of the Photogrammetry, Remote Sensing and Spatial Information Science. XXIV International CIPA Symposium 2013, Strasbourg, France, XL-5/W2, pp. 55-60.

BALLARIN, M., GUERRA, F. and SPERTI, L., 2013. Instruments and Methods for the Survey and Analysis of Amphitheatres, CAA2012. Archaeology in the Digital Era. Papers from the 40th Annual Conference of Computer Applications and Quantitative Methods in Archaeology (CAA), Southampton, United States, pp. 147-153.

BELUSSI, A., MIGLIORINI, S. and GROSSI, P., 2015. Managing Time Dimension in the Archaeological Urban Information System of the Historical Heritage of Rome and Verona, CAA2014. $21^{\text {st }}$ Century Archaeology. Concepts, methods and tools. Proceedings of the $42^{\text {nd }}$ Annual Conference on Computer Applications and Quantitative Methods in Archaeology, Paris, France, pp. 235-244.

COUGHENOUR, C. M., VINCENT, M. L., DE KRAMER, M., SENECAL, S., FRITSCH, D., FLORES GUTTIÉRREZ, M., LOPEZ-MENCHERO BENDICHO, V. M. and IOANNIDES, M., 2015. Embedding Knowledge in 3D Data Frameworks in Cultural Heritage. ISPRS Annals of the Photogrammetry, Remote Sensing and Spatial Information Science. $25^{\text {th }}$ International CIPA Symposium 2015, Taipei, Taiwan, II-5/W3, pp. 47-52. DOI: 10.5194/isprsannals-II-5-W3-47-2015

CRIPPS, P., 2013. Places, People, Events and Stuff; Building Blocks for Archaeological Information Systems, CAA2012. Archaeology in the Digital Era, Volume II. e-Papers from the 40th Annual Conference of Computer Applications and Quantitative Methods in Archaeology (CAA), Southampton, United States, pp. 487-497.

DE ROO, B., DE MAEYER, P. and BOURGEOIS, J., 2013a. On the Way to a 4D Archaeological GIS: State of the Art, Future Directions and Need for standardization, Proceedings of the 2013 digital heritage international congress, 2, Marseille, France, pp. 617-620.

DE ROO, B., VAN DE WEGHE, N., BOURGEOIS, J. and DE MAEYER, P. 2013b. The Temporal Dimension in a 4D Archaeological Data Model: Applicability of the Geoinformation Standard, ISPRS Annales of the Photogrammetry, Remote Sensing and Spatial Information Sciences, Volume II-2/W1, Istanbul, Turkey, pp. 111-121.

DE ROO, B., OOMS, K., BOURGEOIS, J. and DE MAEYER, P., 2014. Bridging Archaeology and GIS: Influencing Factors for a 4D Archaeological GIS, Digital heritage: progress in cultural heritage: documentation, preservation, and protection. 5th International conference on Cultural Heritage (EuroMed 2014), Limassol, Cyprus pp. 186-195.

DE RUNZ, C., 2008. Imperfection, temps et espace : modélisation, analyse et visualisation dans un SIG archéologique, Doctoral Dissertation, University of Reims Champagne-Ardenne.

DELL'UNTO, N., LANDESCHI, G., LEANDER TOUATI, A.-M., DELLEPIANE, M., CALLIERI, M. and FERDANI, D., 2016. Experiencing Ancient Buildings from a 3D GIS Perspective: a Case Drawn from the Swedish Pompeii Project, Journal of Archaeological Method and Theory, 23(1), pp. 73-94. DOI: 10.1007/s10816-014-9226-7

DOULAMIS, A., DOULAMIS, N., IOANNIDES, C., CHRYSOULI, C., GRAMMALIDIS, N., DIMITROPOULOS, K., POTSIOU, C., STATHOPOULOU, E. K. and IOANNIDES, M., 2015. 5D Modelling: an Efficient Approach for Creating Spatiotemporal Predictive 3D Maps of Large-Scale Cultural Resources. ISPRS Annals of the Photogrammetry, Remote Sensing and Spatial Information Science. $25^{\text {th }}$ International CIPA Symposium 2015, Taipei, Taiwan, II-5/W3, pp. 61-68. DOI: 10.5194/isprsannals-II-5-W3-61-2015

ENTWISTLE, J., MCCAFFREY, K. and ABRAHAMS, P., 2009. Three-Dimensional (3D) Visualization: the Application of Terrestrial Laser Scanning in the Investigation of Historical Scottish Farming Townships, Journal of Archaeological Science, 36(3), pp. 860-866. DOI: 10.1016/j.jas.2008.11.018

HASKIYA, D., 2002. Developing an Information System for Archaeological Sites and Monuments - Data Model and Construction, Archaeological Informatics: Pushing the Envelope. CAA2001. Computer Applications and Quantitave Methods in Archaeology. Proceedings of the $29^{\text {th }}$ Conference, Gotland, Sweden, pp. 49-52.

HALLOT, P., STEWARD, K. and BILLEN, R., 2015. Les états spatio-temporels d'existence et de présence. Vers une définition des relations entre objets absents ou inexistants, Revue internationale de Géomatique, 25(2), pp. 173-196. DOI: $10.3166 /$ RIG.25.

HOUSHIAR, H., BORRMANN, D., ELSEBERG, J., NÜCHTER, A., NÄTH, F. and WINKLER, S., 2015. CASTLE3D - A Computer Aided System for Labelling Archaeological Excavations in 3D. ISPRS Annals of the Photogrammetry, Remote Sensing and Spatial Information Science. $25^{\text {th }}$ International CIPA Symposium 2015, Taipei, Taiwan, II-5/W3, pp. 111-118. DOI: 10.5194/isprsannals-II-5-W3-111-2015

KOEHL, M., MEYER, E., KOUSSA, C. and LOTT C., 2008. SIG 3D et 3D dans les SIG: Application aux modèles patrimoniaux, GéoEvènement 2008, Versailles, France, pp. 1-15. 
LANDESCHI, G., DELL'UNTO, N., FERDANI, D., LINDGREN, S. and LEANDER TOUATI, L., 2015. Enhanced 3D-GIS: Documenting Insula V 1 in Pompeii, CAA2014. $21^{\text {st }}$ Century Archaeology. Concepts, methods and tools. Proceedings of the $42^{\text {nd }}$ Annual Conference on Computer Applications and Quantitative Methods in Archaeology, Paris, France, pp. 349-360.

LAURENZA, S. and PUTZOLU, C., 2001. From Stratigraphic Unit to the Mouse: a GIS Based System for the Excavation of Historical Complex. The Case Study of Pompeii, Archaeological Informatics: Pushing the Envelope. CAA2001. Computer Applications and Quantitative Methods in Archaeology. Proceedings of the 29th Conference, Gotland, Sweden, pp. 93-104.

LEICA GEOSYSTEMS AG, 2015. Leica ScanStation P30/P40. Available: http://www.leicageosystems.be/downloads123/hds/hds/general/brochures-datasheet/Leica ScanStation P30P40 DS HERITAGE en.pdf $[4 / 10,2016]$.

MANFERDINI, A. M., REMONDINO, F., BALDISSINI, S., GAIANI, M. and BENEDETTI, B., 2008. 3D Modeling and Semantic Classification of Archaeological Finds for Management and Visualization in 3D Archaeological Databases. Proceedings of the $14^{\text {th }}$ International Conference on Virtual Systems and MultiMedia (VSMM), Limassol, Cyprus, pp. 221-228.

PALIOU, E., 2013. Reconsidering the Concept of Visualscapes: Recent Advances in the Three-Dimensional Visibility Analysis. In: A. BEVAN and M. LAKE, eds, Computational Approaches to Archaeological Spaces. Walnut Creek: Left Coast Press, pp. 243-265.

ROBLES ORTEGA, M. D., ORTEGA ALVARADO, L. and FEITO HIGUERUELA, F. R., 2015. Avances en systemas de Información Espacial 3D. Applicaciones en patrimonio y arqueología virtual. Virtual Archaeology Review, 6(12), pp. 77-91.

TRIMBLE NAVIGATION LIMITED, 2012. Trimble TX5 Scanner. Datasheet. Available: http://trl.trimble.com/docushare/dsweb/Get/Document-628869/022504-122 Trimble TX5 DS 1012 LR.pdf [4/10, 2016].

VAN RUYMBEKE, M., CARRÉ, C., DELFOSSE, V., PFEIFFER, M. and BILLEN, R., 2015. Towards an Archaeological Information System: Improving the Core Data Model, CAA2014. 21st Century Archaeology. Concepts, methods and tools. Proceedings of the 42nd Annual Conference on Computer Applications and Quantitative Methods in Archaeology, Paris, France, pp. 245-253.

WULFF, R. and KOCH, R., 2013. Image-Based 3D Documentation of Archaeological Trenches Considering Spatial, Temporal and Semantic Aspects, CAA2012. Archaeology in the Digital Era, Volume II. e-Papers from the 40th Annual Conference of Computer Applications and Quantitative Methods in Archaeology (CAA), Southampton, United States, pp. 324-336. 